320

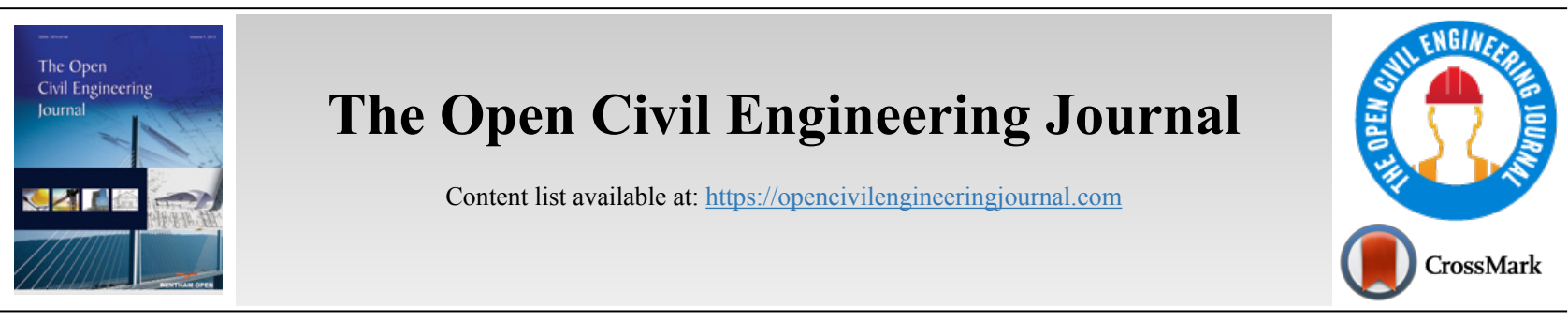

RESEARCH ARTICLE

\title{
Concrete Microstructure Study on the Effect of Sisal Fiber Addition on Sugarcane Bagasse Ash Concrete
}

Constance Tunje ${ }^{1, *}$, Richard Onchiri ${ }^{2}$ and Joseph Thuo ${ }^{3}$

${ }^{\prime}$ Department of Civil Engineering, Pan African University, Institute for Basic Sciences, Technology and Innovation, Hosted at Jomo Kenyatta, Nairobi, Kenya, University of Agriculture and Technology, Nairobi, Kenya

${ }^{2}$ Department of Building and Civil Engineering, Technical University of Mombasa, Mombasa, Kenya

${ }^{3}$ Department of Civil Engineering, Dedan Kimathi University of Technology, Nyeri, Kenya

\begin{abstract}
:
Background:

Concrete made using sugarcane bagasse ash as a cement replacement is associated with a reduction in split tensile strength and therefore a need to establish the possible causes of tensile strength reduction and explore ways of mitigating that reduction.

Objective:

The aim of this study is to establish the possible causes of tensile strength reduction in sugarcane bagasse ash concrete and determine the effect of sisal fiber addition on its mechanical properties.

Methods:

Scanning Electron Microscopy was first done to analyse concrete microstructure in establishing the possible causes of tensile strength reduction in sugarcane bagasse ash concrete. Thereafter, sisal fiber addition was done by varying aspect ratios and percentages. The effect of the addition was determined on the mechanical properties of bagasse ash concrete accompanied by microstructure studies on extracted fibers and split surfaces of concrete.

\section{Results:}

Concrete microstructure studies revealed that wider cracks due to drying shrinkage and poor bonding properties of sugarcane bagasse ash are the possible causes of tensile strength reduction in bagasse ash concrete. Sisal fiber addition improved the mechanical properties of bagasse ash concrete. Microstructure studies portrayed effective bridging of cracks and good adhesive properties of the fibers.

\section{Conclusion:}

Sisal fibers can be used to improve on the mechanical properties of sugarcane bagasse ash concrete with 100 aspect ratio and $1.5 \%$ addition being the optimal combination.
\end{abstract}

Keywords: Microstructure, Scanning electron microscopy, Sugarcane bagasse ash, Sisal fibers, Tensile strength, Aspect ratio, Microcracking, Concrete.

\begin{tabular}{|l|l|l|l|} 
Article History & Received: April 29, 2021 & Revised: July 11, 2021 & Accepted: July 15, 2021
\end{tabular}

\section{INTRODUCTION}

\subsection{Background of the Study}

Environmental pollution represents a major concern for society in recent years. This has prompted researchers all over

"Address correspondence to this author at Department of Civil Engineering, Pan African University, Institute for Basic Sciences, Technology and Innovation, Hosted at Jomo Kenyatta University of Agriculture and Technology, Nairobi, Kenya; Tel: +254 713664207; E-mail: cmtunje@gmail.com, the world today to focus on ways of utilizing either industrial or agricultural waste as a source of raw materials for industry [1]. Ordinary Portland cement is one of the concrete constituents. It is the most expensive material in concrete and during its production, carbon dioxide is released into the atmosphere. Estimates from the International Energy Agency show that cement production accounts for $7 \%$ of all global carbon emissions. According to a survey of Portland Cement Association (PCA) members, for every $1000 \mathrm{~kg}$ of Portland Cement produced, an average of $927 \mathrm{~kg}$ of $\mathrm{CO}_{2}$ is emitted [2]. 
The problems on pollution and cost of cement have prompted scholars to try and find appropriate methods of making cement with several admixtures, to try and solve them.

Sugarcane bagasse ash (SCBA) is a residue obtained from the burning of bagasse in the sugar industry after sugarcane is crushed to extract the juice. Several studies have concluded that SCBA is pozzolanic in nature because of its silica content and can be used as a cement replacement material [3]. The use of bagasse ash as a cement replacement material has been studied and has shown positive results in terms of compressive strength and durability. However, it is associated with a reduction in split tensile strength. Ways of improving this property need to be explored and one of them is by using fibers in concrete.

Natural fibers have become an attractive alternative to synthetic fibers because they are cheap and locally available in many countries. So, their use as a construction material for increasing the properties of composites costs very little [4]. However, there are durability concerns associated with the use of natural fibers in cement-based matrices. Various studies have recommended the use of natural fibers with cementitious supplementary materials to improve the durability aspect.

\subsection{Previous Research Relevant to the Study}

\subsubsection{Effect of Sugarcane Bagasse Ash on Concrete Properties}

Studies on the effect of SCBA on concrete have been done by various researchers and reports have shown that SCBA gives positive results on mechanical properties of concrete, especially on the compressive strength. Kotresh et al. [1] studied the performance of sugarcane bagasse ash waste as a concrete cement using M40 grade concrete and reported higher strength at $10 \%$ SCBA replacement. Another study by Lakshmi \& Ragupathy [3] on the effect of sugarcane bagasse ash on strength properties of concrete on M25 grade concrete gave $14.41 \%$ increment on compressive strength at $10 \%$ cement replacement. Similar results were obtained by Kumar et al. [5], where an improvement in compressive strength was observed with $10 \%$ cement replacement with SCBA being optimal on grade M35 concrete. Beyond 10\% replacement, a reduction in compressive strength was observed in all studies.

However, SCBA has a negative impact on the tensile strength of concrete. Studies on the effect of SCBA on concrete have shown that there is a reduction in tensile strength with the addition of SCBA on concrete. Namakula et al. [6] studied the effect of SCBA on concrete and reported a reduction in tensile strength at both 7 and 28 days. At 7 days, the reduction was $30.7 \%$ and $20 \%$ at 28 days for $15 \%$ replacement. Kotresh et al. [1] observed similar results where there was a decrease in tensile strength of concrete upon addition of SCBA, and the reduction was $16.57 \%$ and $18.64 \%$ for 10 and 15 percent replacements. The reduction was assumed to be due to the poor bonding properties of SCBA.

Mwero [7] conducted a study on the behavior of sugarcane waste fiber ash as a cementing material and tensile splitting strength decreased sharply with an increase in ash. The drop was about $30 \%$ at $6 \%$ replacement. The reduction in tensile strength was assumed to have resulted from shrinkage that could have cracked some of the already formed bonds [7].

Alao [8] studied the tensile splitting strength of SCBA Concrete and reported a decrease in strength by $3.03 \%, 7.2 \%$ and $12.12 \%$ compared to the control at 7 days and also a reduction of $7.33 \%, 10.67 \%$ and $14.33 \%$ at 28 days for $10 \%$, $15 \%$ and $20 \%$ replacements respectively. According to Alao [8], the reduction in tensile strength could be as a result of reduced bonding properties of SCBA in constituent materials in concrete as compared to cement.

Recommendations were given for further research on exploring ways of mitigating the loss in tensile strength observed and improving the bonding properties of sugarcane bagasse ash.

\subsubsection{Effect of Sisal Fibers on Concrete Properties}

Various studies have been carried out on the effect of sisal fibers on concrete properties. Results have shown that sisal fibers have a positive effect on the mechanical properties of concrete. Priyankarani and Srichandana [9] studied sisal fiber reinforced concrete and the results showed an increase of compressive strength to $1.5 \%$ addition. Split tensile strength increased to an increment of $19.57 \%$ at $3 \%$ addition. Flexural strength increased to an optimum of $1.5 \%$ and a drop was observed in 2 and 3\% sisal fiber.

Okeola et al. [10] reported that split tensile strength was enhanced with an increase in fiber addition to an optimum of $1 \%$ where there was an increment of $52.17 \%$. However, there was a decrease in compressive strength upon addition of sisal fibers and reported that the reduction in workability and adhesive properties between the surface of the fiber and cement could have been the cause for reduction in compressive strength as observed.

Research done by Dhanasekar et al. [11] on the strength and durability evaluation of sisal fiber reinforced concrete showed that the compressive strength, tensile strength and flexural strength of concrete increase with an increase in sisal fiber addition. M40 was used in the study. Venkateshwaran \& Kalaiyarrasi [12] also reported improvements in mechanical properties of concrete with sisal fibers.

A study on durability of natural sisal fiber reinforced cement-based composites by deKlerk [13] reported that supplementary cementitious materials proved effective in mitigating degradation and recommended the application of fibers with pozzolans for enhancement of durability.

\subsection{Research Gap}

From the literature review, SCBA has proved to be a suitable material for pozzolana in concrete. However, the use of bagasse ash addition in concrete has been limited due to shortcomings associated with the split tensile strength and various authors have recommended on exploring ways of improving these properties.

This study, therefore, looks into the possible causes of tensile strength reduction in SCBA concrete with the use of concrete microstructure techniques and also explores the 
optimal inclusion of treated sisal fibers to SCBA concrete to enhance its mechanical properties such as split tensile strength.

\section{MATERIALS AND METHODS}

The materials required for the study were Ordinary Portland Cement, Sugarcane Bagasse Ash, water, fine aggregates, coarse aggregates and sisal fibers. Material properties were determined to check their suitability for the production of normal weight concrete.

\subsection{Material Properties}

\subsubsection{Cement}

Ordinary Portland Cement 42.5 CEM 1, which is locally manufactured in Kenya conforming to specifications of BS EN 197-1:2011 [14], was used. Tables 1 and 2 show the physical and chemical properties of cement. The cement sample was analyzed by X-Ray Fluorescence (XRF) for its chemical composition.

\section{Table 1. Physical properties of cement}

\begin{tabular}{|c|c|c|}
\hline Property & Result & BS EN 197-1:2011 [14] Requirements \\
\hline Specific gravity & 3.12 & Not greater than 3.19 (PCA) \\
\hline Consistency & $34.8 \%$ & $25-35 \%$ \\
\hline Initial setting time & $100 \mathrm{~min}$ & $\geq 60 \mathrm{~min}$ \\
\hline Final setting time & $280 \mathrm{~min}$ & $\leq 375 \mathrm{~min}$ \\
\hline Soundness & $5 \mathrm{~mm}$ & $\leq 10 \mathrm{~mm}$ \\
\hline
\end{tabular}

\subsubsection{Sugarcane Bagasse Ash}

Sugarcane bagasse ash was obtained from Mumias sugar company in western Kenya. The ash was produced from the bagasse which is used as fuel in boilers, burnt in the range of 500 to 800 degrees Celsius. It was then standardized by sieving using a $75 \mu \mathrm{m}$ sieve. Chemical properties of SCBA were analyzed by X-Ray Fluorescence (XRF) and are shown in Table 3 which were compared to Fly ash specifications [15].

Table 2. Chemical properties of cement (OPC 42.5 CEM 1).

\begin{tabular}{|c|c|c|}
\hline Element & Percentage Composition (\%) & BS EN 00197-1: 2011 [14] \\
\hline Calcium as $\mathrm{CaO}$ & 76.24 & \multirow[t]{2}{*}{ Ratio: $\mathrm{CaO} / \mathrm{SiO}_{2} \geq 2$} \\
\hline Silica as $\mathrm{SiO}_{2}$ & 12.90 & \\
\hline Aluminium as $\mathrm{Al}_{2} \mathrm{O}_{3}$ & 3.34 & $\leq 8 \%$ \\
\hline Sulphur as $\mathrm{S}$ & 2.73 & - \\
\hline Iron as $\mathrm{Fe}_{2} \mathrm{O}_{3}$ & 2.71 & - \\
\hline Phosphorus as $\mathrm{P}_{2} \mathrm{O}_{5}$ & 1.13 & - \\
\hline Potassium as $\mathrm{K}_{2} \mathrm{O}$ & 0.31 & - \\
\hline Titanium as $\mathrm{TiO}$ & 0.23 & - \\
\hline Strontium as $\mathrm{Sr}$ & 0.13 & - \\
\hline Zinc as $\mathrm{ZnO}$ & 0.09 & - \\
\hline Manganese as $\mathrm{MnO}$ & 0.03 & - \\
\hline Zirconium as $\mathrm{Zr}$ & 0.03 & - \\
\hline Copper as $\mathrm{CuO}$ & 0.03 & - \\
\hline Vanadium as $\mathrm{V}_{2} \mathrm{O}_{5}$ & 0.01 & - \\
\hline Loss of Ignition & $1 \%$ & $\leq 5 \%$ \\
\hline
\end{tabular}

Table 3. Chemical properties of SCBA.

\begin{tabular}{|c|c|c|}
\hline Element & Percentage Composition (\%) & Fly Ash (BS EN 450-1:2012) [15] \\
\hline Silica as $\mathrm{SiO}_{2}$ & 76.53 & Greater than 25\% \\
\hline Iron as $\mathrm{Fe}_{2} \mathrm{O}_{3}$ & 6.35 & - \\
\hline Potassium as $\mathrm{K}_{2} \mathrm{O}$ & 5.64 & Less than $10 \%$ \\
\hline Calcium as $\mathrm{CaO}$ & 5.21 & - \\
\hline Aluminium as $\mathrm{Al}_{2} \mathrm{O}_{3}$ & 2.94 & \\
\hline Phosphorus as $\mathrm{P}_{2} \mathrm{O}_{5}$ & 1.82 & Less than 5\% \\
\hline Manganese as $\mathrm{MnO}$ & 0.41 & - \\
\hline Titanium as $\mathrm{TiO}$ & 0.6 & - \\
\hline Sulphur as $\mathrm{S}$ & 0.23 & \\
\hline Zinc as $\mathrm{ZnO}$ & 0.09 & - \\
\hline Chromium as $\mathrm{Cr} \mathrm{O}_{3}$ & 0.03 & - \\
\hline Zirconium as $\mathrm{Zr}$ & 0.03 & - \\
\hline Rubidium as $\mathrm{Rb}$ & 0.02 & - \\
\hline Copper as $\mathrm{CuO}$ & 0.02 & \\
\hline
\end{tabular}




\subsubsection{Fine Aggregates}

Fine aggregates used were river sand obtained locally in Kenya. It conformed to BS EN 12620:2013 [16] and its grading complied with the general grading requirements provided in Table 2 of BS EN 12620:2013 [16]. Only particle sizes passing through $5 \mathrm{~mm}$ sieve were considered for the study. Table 4 shows its properties and Fig. (1) shows the grading of fine aggregates.

\subsubsection{Coarse Aggregates}

Coarse aggregates for the study were obtained from Warren Concrete Limited-Nairobi, Kenya and they were of $20 \mathrm{~mm}$ maximum size. Before use, they were washed to remove silt and sun-dried. Properties of coarse aggregates are as shown in Table 5 and Fig. (2) shows the grading of coarse aggregates.

Table 4. Properties of fine aggregates.

\begin{tabular}{|c|c|c|}
\hline Property & Result & BS EN 12620-2013 [16] Requirements \\
\hline Grading & Grading curve within upper and lower limits & Grading curve should fall within the envelope \\
\hline Fineness modulus & 2.76 & Medium grading range (1.5-2.8) \\
\hline Bulk density & $1567.5 \mathrm{~kg} / \mathrm{m}^{3}$ & $1200-1750 \mathrm{~kg} / \mathrm{m}^{3}$ \\
\hline Water absorption & $2.1 \%$ & $<3 \%$ \\
\hline Specific gravity & 2.5 & $2.4-2.9$ \\
\hline
\end{tabular}

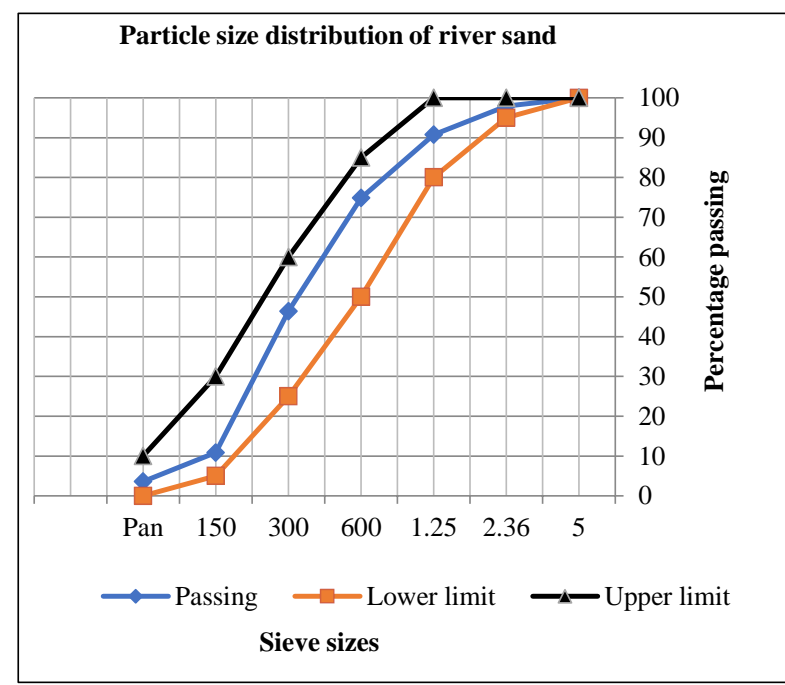

Fig. (1). Particle size distribution of river sand.

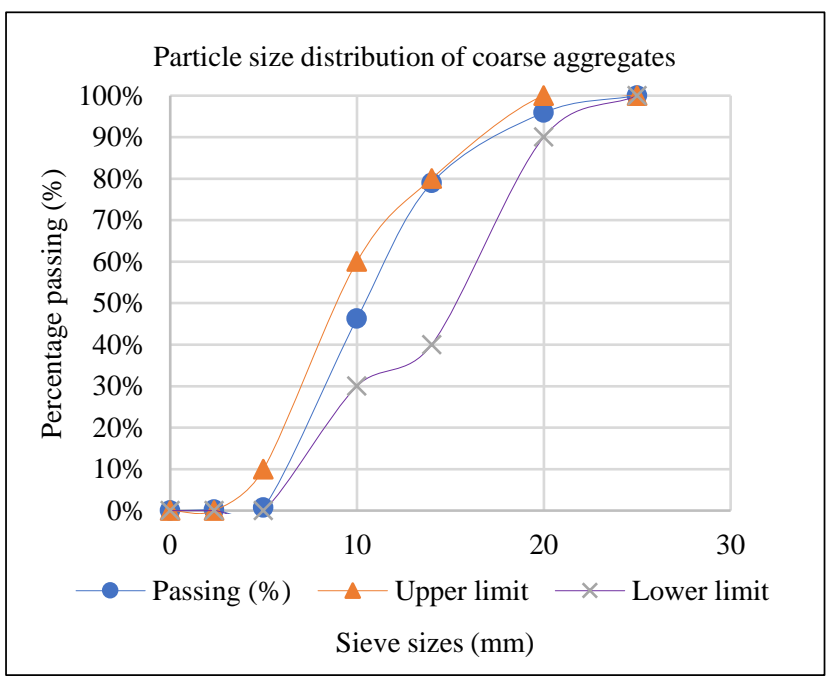

Fig. (2). Particle size distribution of coarse aggregates. 
Table 5. Properties of coarse aggregates

\begin{tabular}{|c|c|c|}
\hline Test & Result & $\begin{array}{c}\text { BS EN 12620-2013 [16] } \\
\text { requirements }\end{array}$ \\
\hline Grading & $\begin{array}{c}\text { Grading curve within } \\
\text { the upper and lower } \\
\text { limits }\end{array}$ & $\begin{array}{c}\text { Grading curve should fall } \\
\text { within the envelop }\end{array}$ \\
\hline Bulk Density & $1516.3 \mathrm{Kg} / \mathrm{m}^{3}$ & $\begin{array}{c}\text { Normal weight concrete } \\
(1200-1750) \mathrm{kg} / \mathrm{m}^{3}\end{array}$ \\
\hline Specific gravity & $\begin{array}{c}\text { Apparent-2.57 } \\
\text { Saturated Surface } \\
\text { Dry-2.54 } \\
\text { Oven dry-2.45 }\end{array}$ & $2.4-2.9$ \\
\hline Water absorption & $2.86 \%$ & $0.1-3 \%$ \\
\hline $\begin{array}{c}\text { Aggregate } \\
\text { Crushing Value }\end{array}$ & 15.17 & $\begin{array}{c}\text { Less than } 30 \text { for many } \\
\text { concrete applications }\end{array}$ \\
\hline
\end{tabular}

\subsubsection{Sisal Fibers}

UG grade A Sisal fiber was obtained locally from Rea Vipingo Plantation Limited. UG Grade A Sisal fiber is considered to be of good quality because of its high level of purity and less foreign matter. Fiber diameter was measured with a micrometer and obtained as $0.4 \mathrm{~mm}$. The fiber was cut in lengths of 20, 40 and $60 \mathrm{~mm}$, which translates to aspect ratios (AR) of 50, 100 and 150. It was pre-treated using $6 \%$ Sodium hydroxide solution for 3 hours to dissolve lignin and any extractions on the surface to improve the adhesive properties and water absorption and later washed with distilled water. It was then sun-dried for at least 3 days and was ready for use. The following are the sisal fiber properties (Table 6) [17].

Table 6. Properties of sisal fiber.

\begin{tabular}{|c|c|}
\hline Property & Value \\
\hline Colour & Creamish white \\
\hline Length & $90-110 \mathrm{~cm}$ \\
\hline Purity & $98-99.5 \%$ \\
\hline Foreign matter & $0.5 \%$ \\
\hline
\end{tabular}

The effect of the sisal fiber alkaline pretreatment was determined on the fiber structure by microstructure techniques using Scanning Electron Microscope on both raw and treated sisal fiber. This was done to investigate the changes in the fiber structure as a way of improving the adhesive properties of the sisal fibers hence improving the stress transfer between the fiber and the matrix.

\subsection{Mix Design}

Normal concrete mix design was done in accordance with Design of Normal Concrete mixes by Building Research Establishment [18]. Compressive strength Class C25/30 for normal weight concrete was designed with minimum characteristic cube strength fck, cube of $30 \mathrm{~N} / \mathrm{mm}^{2}$. Mix design output quantities are shown in Table 7. Each mix batch constituted $0.06 \mathrm{~m}^{3}$ of concrete.

\subsection{Mix Proportions}

A total of 14 mixes were prepared. These were obtained by the first preparation of the control mix, which was $100 \%$ cement with no sisal fiber addition. Bagasse ash concrete mix was then prepared using $10 \%$ cement replacement with SCBA. 12 more mixes were done to determine the effect of sisal fibers on bagasse ash concrete by varying sisal fiber content by $0.5 \%$, $1 \%, 1.5 \%$ and $2 \%$ by weight of cement and also varying the sisal fiber aspect ratio by 50,100 and 150 . Sisal fiber dosage is given in Table 8 based on the mix design output quantities. Bagasse ash's optimal percentage of $10 \%$ was used based on literature.

Table 7. Mix Design Output Quantities.

\begin{tabular}{|c|c|c|c|c|}
\hline Quantities & $\begin{array}{c}\text { Cement } \\
(\mathbf{k g})\end{array}$ & $\begin{array}{c}\text { Water } \\
(\mathbf{k g})\end{array}$ & $\begin{array}{c}\text { Fine } \\
\text { aggregates (kg) }\end{array}$ & $\begin{array}{c}\text { Coarse } \\
\text { aggregates (kg) }\end{array}$ \\
\hline Per m $^{3}$ & 365 & 190 & 660 & 1125 \\
\hline Per $0.06 \mathrm{~m}^{3}$ & 21.9 & 11.4 & 39.6 & 67.5 \\
\hline
\end{tabular}

\subsection{Batching and Mixing}

All the materials used for the study were batched by weight. Individual material weights as per the mix design output calculations were weighed, followed by batching of SCBA $(10 \%$ of cement weight) and sisal fiber $(0-2 \%)$ by cement weight. Mixing was done by a mixer.

Table 8. Sisal fiber dosage by weight of cement.

\begin{tabular}{|c|c|c|c|c|}
\hline Fiber percentages by weight of cement & $\mathbf{0 . 5 0} \%$ & $\mathbf{1 \%}$ & $\mathbf{1 . 5 0 \%}$ & $\mathbf{2 \%}$ \\
\hline $\begin{array}{c}\text { Weight in kg per } \mathbf{0 . 0 6 \mathbf { m } ^ { 3 }} \text { of concrete } \\
\text { mix }\end{array}$ & 0.1095 & 0.219 & 0.3285 & 0.438 \\
\hline
\end{tabular}

\subsection{Casting and Curing}

Cubic moulds, cylinders and prismatic moulds were first cleaned and oiled before casting. Cubes for compressive strength, water absorption and density were $100 \mathrm{~mm}$ by 100 $\mathrm{mm}$ in dimension, cylinders for split tensile strength were of $100 \mathrm{~mm}$ diameter and $200 \mathrm{~mm}$ in height and moulds for flexural strength were $150 \mathrm{~mm}$ by $150 \mathrm{~mm}$ by $530 \mathrm{~mm}$ in dimension. After oiling the moulds, they were filled with wellmixed concrete in three layers and vibrated using a poker vibrator. The concrete samples were then left for 24 hours of air curing before demolding. Curing was done in a water curing tank for 7 days and 28 days.

\subsection{Specimen Testing}

\subsubsection{Concrete Microstructure}

Microscopic observation for concrete samples was done using a Scanning Electron Microscope (SEM). The aim of the study was to establish the cause for tensile strength reduction in concrete incorporated with bagasse ash and how this shortcoming is addressed using the sisal fibers. Concrete specimens for both Control and Bagasse Ash concrete cured for 28 days were taken for cutting using a concrete cutter. The samples were marked and cut in $2 \mathrm{~cm}$-by- $2 \mathrm{~cm}$ cubes. After cutting, the samples were placed in a 2.5 diameter sample holder of the SEM machine and observations were done at low vacuum.

The key focus was on the concrete matrix structure and microcracking. For sisal fiber reinforced concrete, attention was also given to fiber paste bonding. 


\subsubsection{Concrete Mechanical Properties}

\subsubsection{Compressive Strength}

The Compressive strength test for this research was determined in accordance with BS EN 12390-3:2002 [19] using Universal Testing Machine (UTM). The test specimens were cubes of dimension $100 \mathrm{~mm}$ by $100 \mathrm{~mm}$. Loading was applied to the specimen using a constant rate without shock and increased continuously until no greater load was sustained. SEM images were also taken on extracted fibers to observe the matrix attachment on the fibers for the determination of the fiber's adhesive properties.

\subsubsection{Split Tensile Strength}

The tensile strength of concrete was determined in accordance with BS EN 12390-6:2009 [20]. Cylindrical specimens of $100 \mathrm{~mm}$ diameter and $200 \mathrm{~mm}$ height were subjected to a compressive force applied to a narrow region along its length resulting in orthogonal tensile force that caused the specimen to fail in tension. SEM images on split surfaces of concrete samples were taken to observe the effectiveness of fibers in bridging gaps and also the fiber-matrix bonding.

\subsubsection{Flexural Strength}

The Flexural strength of concrete was determined in accordance with BS EN 12390-5:2000 [21]. Prismatic specimens of dimension $150 \mathrm{~mm}$ by $150 \mathrm{~mm}$ by $530 \mathrm{~mm}$ were used and loaded in two-point loading.

\section{RESULTS AND DISCUSSION}

\subsection{Effect of Alkaline Pre- treatment on Sisal Fiber Microstructure}

Scanning Electron Microscopy (SEM) images were taken to study the effect of the treatment on the fiber structure and appearance. Images were taken at a magnification of 100 , as shown in Figs. (3 and 4).

Fig. (3) shows a raw sisal fiber. The surface of the fiber looks smooth and also showing some surface microfibrils. The microfibrils exhibited represents the amorphous microfibrils since it's on the primary wall of the fiber structure.

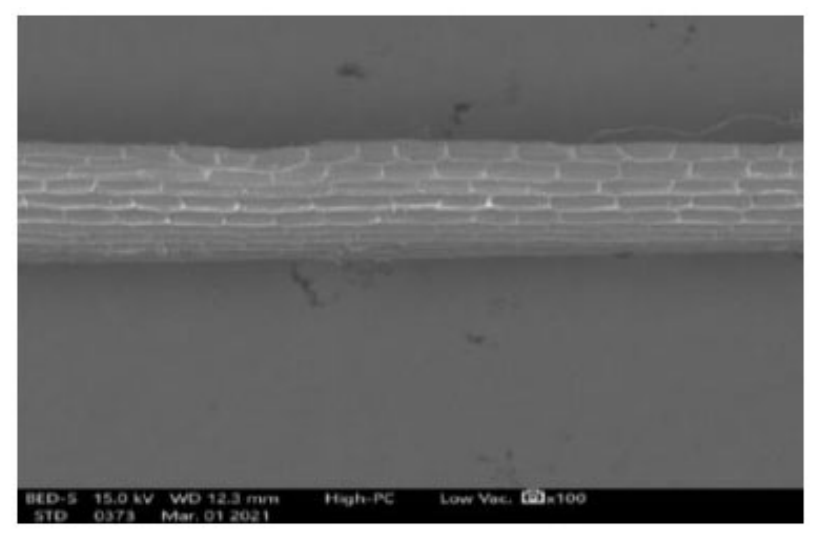

Fig. (3). Raw sisal fiber surface produced by SEM.
One of the challenges with natural fibers is their poor fiber compatibility into the matrix since their cellulose surface is covered by both hemicellulose and lignin components of the fiber at the primary wall, which acts as a weak boundary layer between the fiber and the matrix [22]. The stress distribution capacity in the composite is generally reduced due to the boundary layer at the fiber matrix interface. For better performance in stress transfer in composites, the weak boundary layer has to be removed by chemical treatment.

Fig. (4) shows an alkaline treated sisal fiber. The surface of the fiber is rougher and shows that some surface material has been removed. Apart from improving the fiber hydrophilicity, alkaline treatment of natural fibers also takes out a portion of hemicellulose, lignin and other surface impurities which constitute the weak boundary layer therefore exposing the cellulose crystalline microfibrils to the fiber surface [13]. The treated sisal fiber, in this case, is considered to have better compatibility with the matrix and also the rougher surface further improves the fiber-matrix adhesion compared to the raw sisal fiber [23].

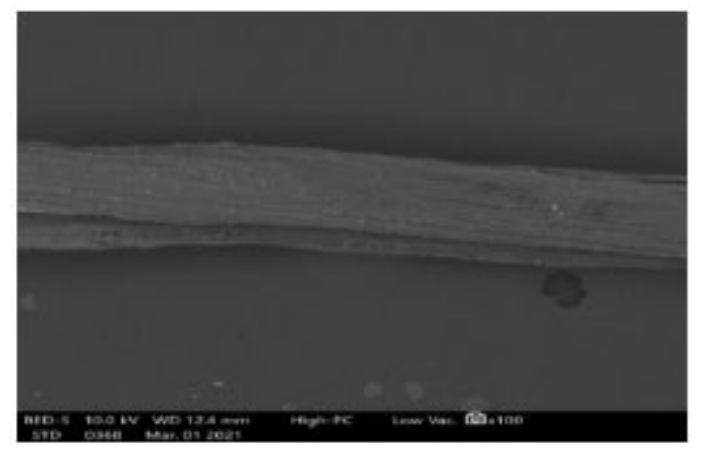

Fig. (4). Alkaline treated sisal fiber surface produced by SEM.

\subsection{Concrete Microstructure Study for Establishing the Possible Causes of Tensile Strength Reduction in SCBA Concrete}

Observation was done at a low vacuum, at $15 \mathrm{Kv}$ accelerating voltage and at a magnification of 1000 . The images obtained are as shown and analyzed below.

Fig. (5a) shows an image of SCBA concrete, measurement of crack widths was taken and as shown, the average width was $3.1745 \mu \mathrm{m}$. Fig. (6a) shows an image of control mix concrete. The cracks were also measured in terms of their thickness and the average crack width was recorded as $1.193 \mu \mathrm{m}$. These cracks observed in the concrete matrix could be due to drying shrinkage of concrete since the samples were observed at 28 days of age. Drying shrinkage is due to the loss of capillary water in the concrete. Cracking occurs due to the increase in tensile stresses brought about by the shrinkage.

In comparison, SCBA concrete has wider cracks than the control and this could be due to its high-water requirement which resulted in higher loss of capillary water compared to the control. Cracks generally reduce the load-carrying capacity of concrete and act as the starting point for the development of larger cracks. This could be one of the reasons for the loss of tensile strength in bagasse ash concrete. 
Another comparison was made with respect to the dense packing and pore structure of the concrete samples. Comparing control mix concrete as shown in Fig. (5) and SCBA concrete in Fig. (6), SCBA concrete looks denser and less porous compared to the control mix. This property explains the improved durability of SCBA concrete as reported by various researchers. However, by concrete technology, there is the" wall effect" of aggregates where aggregates act as mini walls, disrupting the normal parking of the cement grains leading to accumulation of smaller grains in the zone close to the aggregates while larger grains are found further out [24]. Bagasse ash grains being smaller compared to cement grains, are expected to have parked closer to the aggregates and cement further out. Tensile strength in this case is affected in that SCBA having poor bonding properties [6], reduces the bond strength between the aggregates and the paste resulting to the reduction in tensile strength.

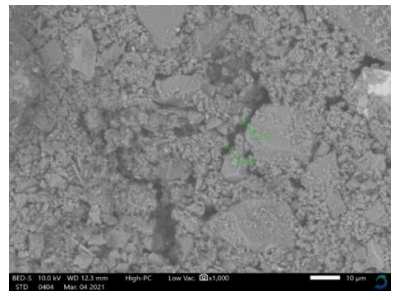

(a) Matrix microcracking

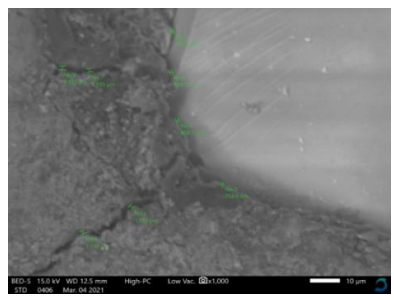

(b)Aggregate-paste interface
Fig. (5). SEM images showing matrix microcracking (a) and aggregate-paste interface (b) in control mix concrete.

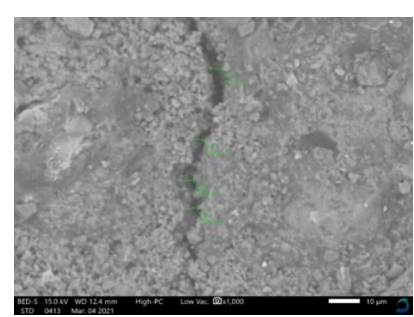

(a)Matrix Microcracking

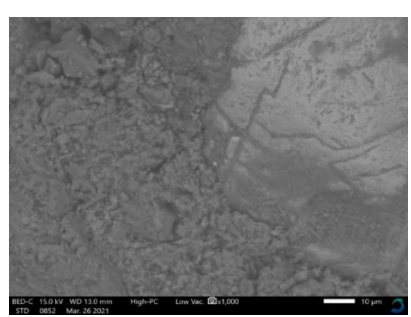

(b) Aggregate-paste interface
Fig. (6). Matrix microcracking (a) and aggregate-paste interface (b) in sugarcane bagasse ash concrete.
Therefore, based on the analysis made, tensile strength reduction in bagasse ash concrete could be as a result of the wider micro-cracks due to high drying shrinkage and poor bonding properties of bagasse ash.

\subsection{Effect of Sisal Fiber Addition on the Mechanical Properties of SCBA Concrete}

\subsubsection{Compressive Strength}

Results on compressive strength are as shown in Fig. (7), showing the effect of both the sisal fiber percentage and length.

Fig. (7) shows that there was an impact on the compressive strength upon addition of SF. At 50AR, there was an increment of $1.48 \%$ and $6.89 \%$ for $0.5 \%$ and $1 \%$ SF addition respectively followed by a decrease of $18.23 \%$ and $21.10 \%$ for $1.5 \%$ and $2 \%$ SF addition respectively compared to SCBA concrete. At $100 \mathrm{AR}$, an increase of $15.28 \%$ and $17.22 \%$ in compressive strength was observed at $0.5 \%$ and $1 \% \mathrm{SF}$ addition but further increase in SF resulted to a reduction of $13.33 \%$ and $31.41 \%$ for $1.5 \%$ and $2 \% \mathrm{SF}$ addition, respectively. Finally, at $150 \mathrm{AR}$, a slight increase in compressive strength of $0.18 \%$ was observed at $0.5 \% \mathrm{SF}$ addition but a steady drop was observed from $1 \% \mathrm{SF}$ addition. The reduction was $11.8 \%, 29.38 \%$ and $36.49 \%$ for $1 \%, 1.5 \%$ and $2 \%$ SF addition respectively. The increase in compressive strength for low SF percentage addition could be as a result of confinement provided by the fiber, which increased the bonding characteristics of concrete [25]. Alsadey \& Salem [26] reported that fibers effectively hold the microcracks in concrete mass resulting in an increase in strength.

Similar results on the improvement of compressive strength upon addition of sisal fibers were reported by Venkateshwaran \& Kalaiyarrasi [12], Dhanasekar et al. [11] and Priyankarani \& Srichandana [9]. However, Okeola et al. [10] reported a decrease in compressive strength with SF addition and argued that it could be a result of reduction in workability and adhesive properties between the surface of the fiber and the cement. In this study, the adhesive properties of fiber and matrix were examined by conducting SEM on extracted fibers. Images from the optimal mix (100 AR 1\%) were also observed to see the fibers' interactions with the concrete.

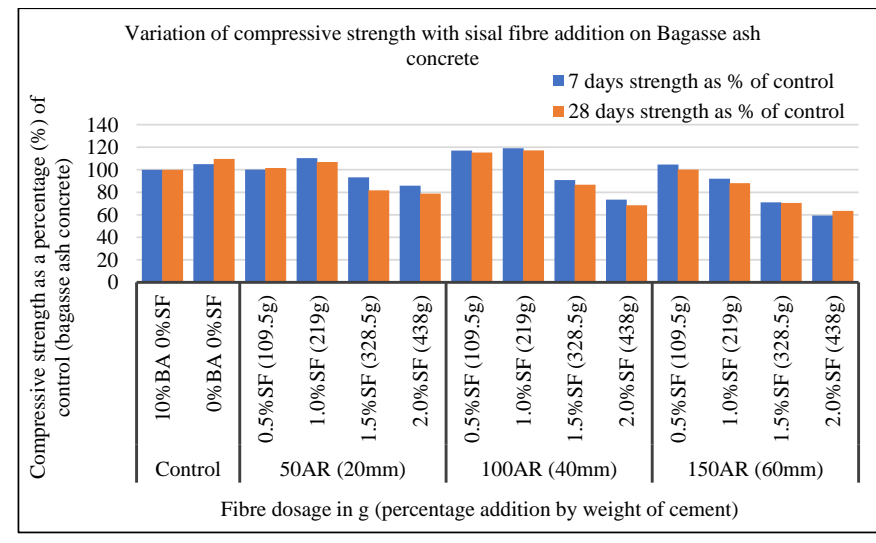

Fig. (7). Effect of sisal fiber percentage on the compressive strength of SCBA concrete. 


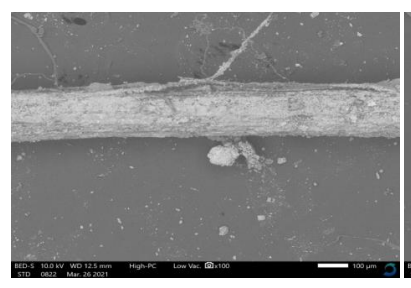

(a)50AR $1 \% \mathrm{SF}$

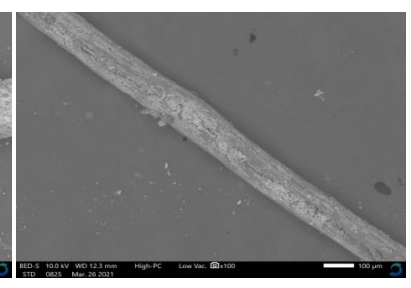

(b) 50AR 2\% SF
Fig. (8). SEM images on extracted fibers from 50AR 1\% (a) and 50AR $2 \%$ (b) showing matrix attachment.

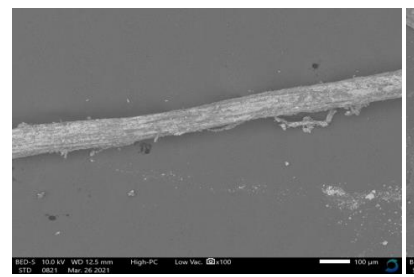

(a)100AR 1\% SF

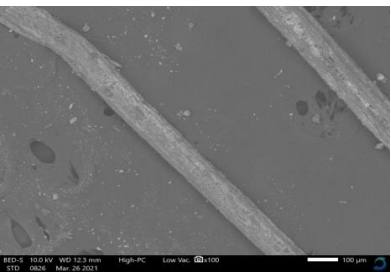

(b) $100 \mathrm{AR} 2 \% \mathrm{SF}$
Fig. (9). SEM images on extracted fibers from 100AR 1\% (a) and $100 \mathrm{AR} 2 \%$ (b) showing matrix attachment.

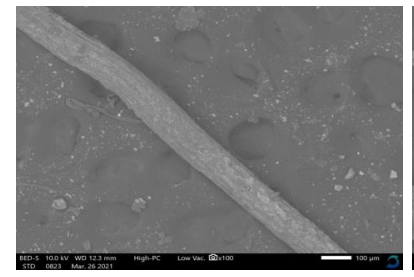

(a)150AR 1\% SF

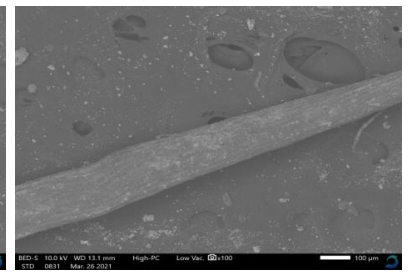

(b) 150AR $2 \% \mathrm{SF}$
Fig. (10). SEM images on extracted fibers from 150AR 1\% (a) and $150 \mathrm{AR} 2 \%$ (b) showing matrix attachment.

The images showed a good matrix attachment on the fibers for low percentages of SF especially for $50 \mathrm{AR}$ and $100 \mathrm{AR}$ as shown in Figs. (8 and 9) which portrayed good adhesive properties of the fibers. For higher SF percentages, the fibers had less matrix attachment as seen in the SEM images in Figs. (8-10) which portrayed poor bonding with the matrix. This explains the reduction in strength with higher sisal fiber addition. SEM images on cut samples of the optimal concrete mix (100AR $1 \%$ SF) also showed a fiber support network inside the matrix and fibers limiting the propagation of cracks (Fig. 11). These fiber mechanisms also explain the increase in compressive strength.

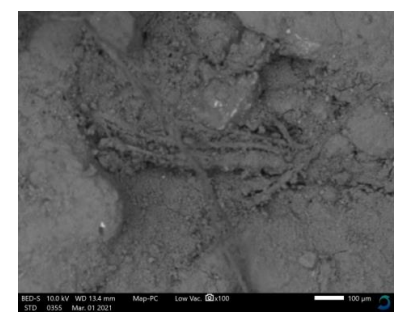

(a)Fiber support network

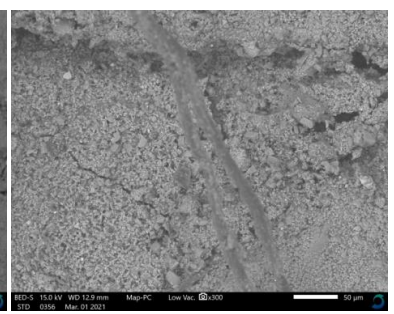

(b) Crack limitation by fibers
Fig. (11). SEM images on cut concrete sample of 100AR 1\% mix showing fiber support network (a) and crack limitation by fibers (b).

\subsubsection{Tensile Strength}

Reduction in tensile strength was the major shortcoming when using bagasse ash as a cement replacement material. SEM images on SCBA concrete revealed that presence of shrinkage cracks in its matrix and poor bonding properties could be the main causes for the reduction in tensile strength. The results of sisal fiber addition on tensile strength of SCBA concrete are shown in Fig. (12).

As shown in Fig. (12), both fiber content and length affect the tensile strength of SCBA concrete. At 50AR, there was an increase in tensile strength of $10.03 \%, 30.67 \%, 29.73 \%$ and $14.52 \%$ for $0.5 \%, 1 \%, 1.5 \%$ and $2 \%$ respectively compared to SCBA concrete. The increase at 100AR was $18.26 \%, 39.58 \%$, $43.75 \%$ and $10.60 \%$ respectively. Finally, at $150 \mathrm{AR}$, improvement was observed at $0.5 \%$ and $1 \% \mathrm{SF}$ addition where $25.82 \%$ and $3.95 \%$ increments were recorded. Based on the 28 days results, the optimal sisal fiber combination was $100 \mathrm{AR}$ $1.5 \%$ with an increment of $43.75 \%$ compared to SCBA concrete.

SEM images on split surfaces of the optimal mix were taken and as observed, bridging of cracks was effective with sisal fibers (Fig. 13).

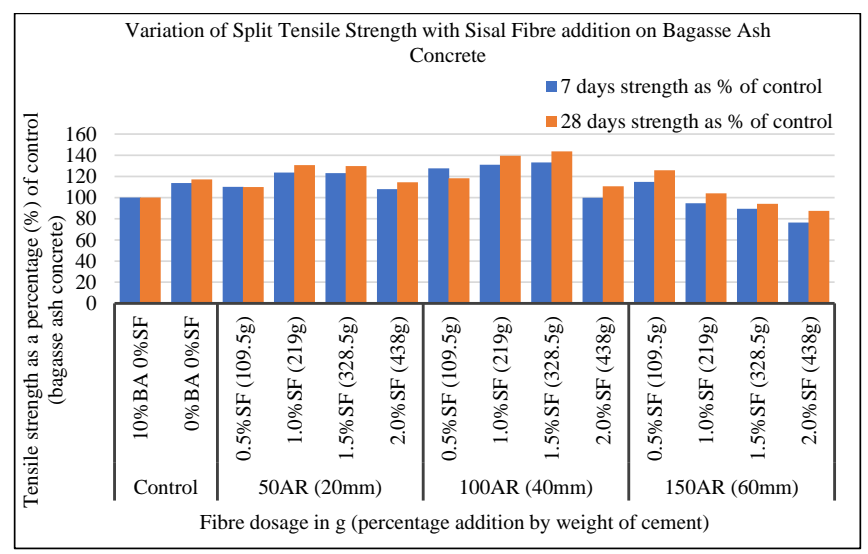

Fig. (12). Effect of sisal fiber addition on the tensile strength of SCBA concrete. 


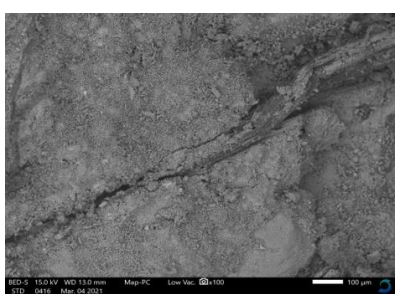

(a)Good bonding of fibers

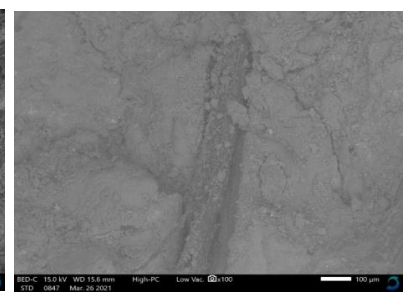

(b) Effective bringing of cracks

Fig. (13). SEM images of split surfaces of 100AR 1.5\%SF.

For fiber reinforced composites, the matrix transfers the load to the fiber through shear stress at the interface therefore, a good bond is required between the matrix and the fiber [27]. As seen in the SEM images, matrix still adheres to the fiber even after failure, which is a clear indication of good adhesion between the fiber and the matrix. For a higher aspect ratio of 150 and higher fiber contents of $2 \%$ (Fig. 14), an accumulation of fibers was seen on the surface. Fiber pull-outs were also observed as evidenced by the observation of voids, indicating poor fiber-matrix bond that resulted in reduced tensile strength.

Increase in tensile strength with length is observed for $0.5 \%, 1 \%$ and $1.5 \%$ SF addition from $20 \mathrm{~mm}$ to $40 \mathrm{~mm}$ length. Stress concentrations at the fiber ends lead to matrix cracking [28] and therefore, shorter fiber lengths will create more fiber ends which act as stress concentration points where failure can occur. With an increase in length, the stress concentration points are minimized and this explains the increase in tensile strength observed. With further increase of length to $60 \mathrm{~mm}$ (150AR), tensile strength is negatively affected and this could be due to the reduced bonding of the fibers as a result of fiber balling.

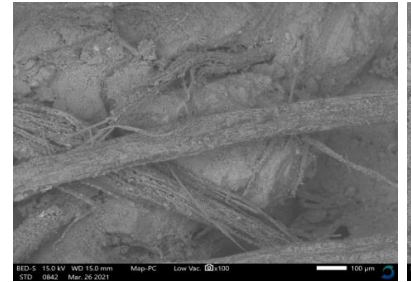

(a)Accumulation of fibers

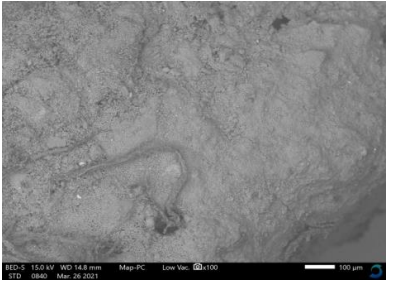

(b) Fiber pull-outs
Fig. (14). SEM images on split surfaces of $150 \mathrm{AR} 2 \% \mathrm{SF}$.

\subsubsection{Flexural Strength}

Flexural strength was determined using prismatic concrete specimen of dimensions $150 \mathrm{~mm}$ by $150 \mathrm{~mm}$ by $530 \mathrm{~mm}$. Twopoint loading was used and testing was done using a Universal Testing Machine at 28 days.

Sisal fiber content had an impact on the flexural strength of SCBA concrete (Fig. 15). At 50AR, there was an improvement of $3.17 \%, 18.20 \%, 15.83 \%$ and $9.54 \%$ for $0.5 \%, 1 \%, 1.5 \%$ and $2.0 \%$ respectively. Flexural strength increment at $100 \mathrm{AR}$ was recorded as $7.3 \%, 19.32 \%$ and $20.49 \%$ for $0.5 \%, 1 \%$ and $1.5 \%$, respectively. Finally, improvement on flexural strength when using $150 \mathrm{AR}$ is $16.27 \%$ for $0.5 \%$ and $0.12 \%$ for $1 \%$. Further increase leads to a reduction in strength. Improvement in flexural strength was also reported by $[9,11,29]$. Dhanasekar et al. [11] reported that the creation of densely compacted medium in cement concrete resulted to an increase in flexural strength.

The trend in flexural strength upon addition of sisal fibers is similar to that of split tensile strength with optimal combination of $100 \mathrm{AR}, 1.5 \% \mathrm{SF}$. This could be due to the fact that flexural strength is also an indirect measure of tensile strength since failure occurs when the tensile stresses developed at the bottom of the beam exceed the flexural strength of the beam.

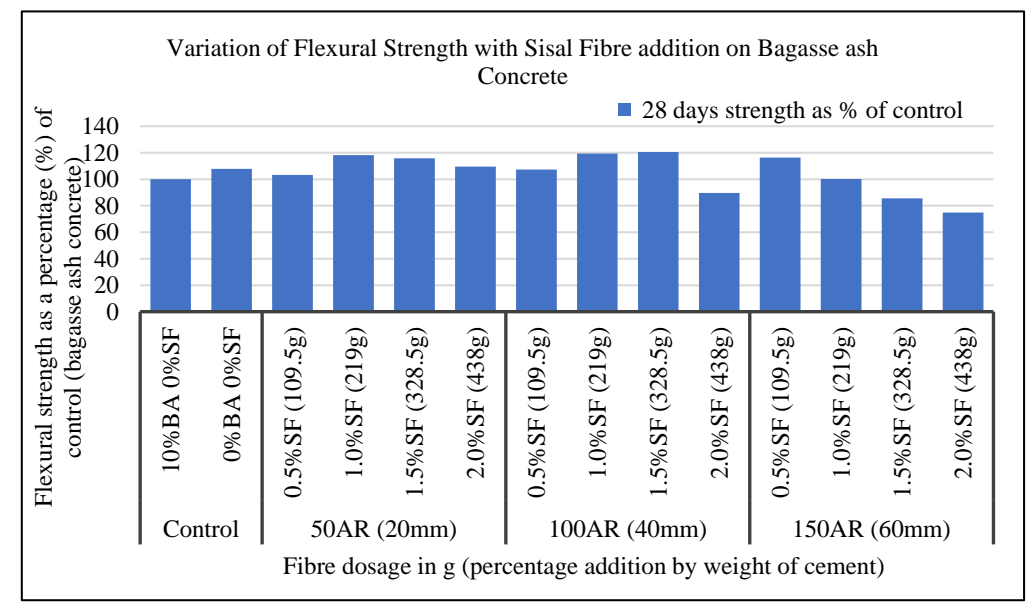

Fig. (15). Effect of sisal fiber addition on the flexural strength of SCBA concrete. 


\section{CONCLUSION}

Based on the results obtained from the study, it can be concluded that;

- Tensile strength reduction in SCBA concrete is a result of wider cracks due to high drying shrinkage of concrete as observed in SEM images and poor bonding of SCBA.

- Sisal fibers can be used to improve the mechanical properties of SCBA concrete since it showed improved results and also effective in bridging micro cracks as observed in SEM images.

- Incorporation of SCBA and sisal fibers in concrete can result in economical and affordable housing.

Further studies on the durability of sisal fibers in SCBA concrete can be investigated to observe the extent of deterioration of the fibers for a longer duration since they are natural fibers.

\section{CONSENT FOR PUBLICATION}

Not applicable.

\section{AVAILABILITY OF DATA AND MATERIALS}

The authors confirm that the data supporting the findings of this study are available within the article.

\section{FUNDING}

None.

\section{CONFLICT OF INTEREST}

The authors declare no conflict of interest, financial or otherwise.

\section{ACKNOWLEDGEMENTS}

Declared none.

\section{REFERENCES}

[1] K. Kotresh, S. Berihe, M. Getahun and Madan, "Study on performance of sugarcane bagasse ash waste as a concrete cement", Int. J. Res. Eng. Tech., vol. vol. 2, no. no. 5, pp. 1-6, 2014.

[2] M. Marceau, and M. Nisbet, VanGeem and Martha Life Cycle Inventory of Portland Cement Manufacture., Portland Cement Association: Skokie, Illinois, 2006.

[3] K. Lakshmi, and R. Ragupathy, "Effect of sugarcane Bagasse ash on strength properties of concrete", Int. J. Res. Eng. Technol., vol. 05, no. 04, pp. 159-164, 2016

[http://dx.doi.org/10.15623/ijret.2016.0504030]

[4] S. Kavitha, and F. Kala, "A review on natural fibers in concrete", Int. J. Adv. Eng. Technol., vol. 1, no. 1, pp. 1-4, 2017.

[5] G. N. Kumar, G. H. Vardhan, and S. V. Bhaskar, "Partial replacement of cement in concrete with sugarcane Bagasse ash and its bahavior in aggressive Environment,", J. Mech. Civil Eng., pp. 29-35.

[6] H. Namakula, R.N. Mutuku, and J.N. Mwero, "Effect of sugarcena bagasse ash on the physical and mechanical properties of plastic fiber reinforced concrete", European Int. J. Sci. Tech., vol. 6, no. 8, pp. 31-41, 2017.

[7] J.N. Mwero, "The effect of partial replacement of cement with surgacane waste fibre ash (SWFA) on mechanical properties of concrete", J. Mater. Civ. Eng., 2013.

[8] D.M.O. Alao, Investigation of performance of lime treated palm Kernel Shell and sugarcane Bagasse ash as partial replacements of Coarse Aggregates and Cement Respectively in concrete, Jomo Kenyatta University of Agriculture and Technology, 2018.

[9] G. Priyankarani, "Experimental study on effects of sisal fiber reinforced concrete", Int. J. Mag. Eng. Tech. Manag. Res., vol. 2, no. 5, pp. 388-392, 2015.

[10] A.A. Okeola, S.O. Abuodha, and J. Mwero, "Experimental investigation of the physical and mechanical properties of sisal fiber reinforced concrete", MDPI; fibers, pp. 1-16.

[http://dx.doi.org/10.3390/fib6030053]

[11] K. Dhanasekar, R. Manikandan, R. Ancil, R.V. Raman, P. Surender, and Selva, "Strength and durability evaluation of sisal fibre reinforced concrete", Int. J. Civil Eng. Tech., vol. 8, no. 9, pp. 741-748, 2017. [IJCIET].

[12] S. Venkateshwaran, and A. Kalaiyarrasi, "Sisal fiber reinforced Concrete", J. Emerg. Technol. Innov. Res., vol. 5, no. 5, pp. 65-69, 2018.

[13] M.D. deKlerk, "The durability of natural sisal fibre reinforced cementbased composite", Stellenbosch University library and Information services, 2015. Available from: http://hdl.handle.net/10019.1/96895

[14] BS EN 197 Part 1, Cement: Composition, specifications and conformity criteria for common cements, British Standard Institution: London, UK, 2015.

[15] BS EN 450 Part 1, Fly Ash for concrete: Definition, specifications and conformity criteria, British Standard Institution: London, UK, 2012.

[16] BS EN 12620, Aggregates for concrete, British Standard Institution: London, UK, 2013. Available from: https://mecegeneraltradingltd.com/product/sisal-fiber-grade-ug-2/

[17] B. Marsh, "Design of normal concrete mixes; Second Edition, Watford: Construction Research Communications Ltd", Available from:

https://mecegeneraltradingltd.com/product/sisal-fiber-grade-ug-2/

[18] B. Marsh, Design of normal concrete mixes., $2^{\text {nd }}$ ed. Construction Research Communications Ltd: Watford, 1997.

[19] BS EN 12390 Part 3, "Testing hardened concrete: Compressive strength of test specimens, British Standard Institution, London, UK", Available from: http://hdl.handle.net/10019.1/96895

[20] BS EN 12390 Part 6, "Testing hardened concrete: Tensile splitting strength of test specimens, British Standard Institution, London, UK", Available from: http://hdl.handle.net/10019.1/96895

[21] "BS EN 12390 Part 5, "Testing hardened concrete: Flexural strength of test specimens," British Standard Institution, London, UK", Available from: 2009. http://hdl.handle.net/10019.1/96895

[22] M.M. Kabir, H. Wang, A. Lau, and F. Cardona, "Effects of chemical treatments on hemp fibre reinforce polyester composites", Appl. Surf. Sci., vol. 276, pp. 13-23, 2013.

[http://dx.doi.org/10.1016/j.apsusc.2013.02.086]

[23] J. Wei, Durability of cement Composites Reinforced with sisal fibers. Columbia University Libraries, 2014.

[24] A.A. Hilal, Microstructure of concrete., IntechOpen Publishers: Anbar, Iraq, 2016.

[http://dx.doi.org/10.5772/64574]

[25] D. S. Dharan, and A. Lal, "Stugy the effect of polypropelene fiber in concrete", Int. Res. J. Eng. Tech. (IRJET), vol. 03, no. 06, pp. 616-619, 2016.

[26] S. Alsadey, and M. Salem, "Influence of polypropylene fiber on strength of concrete", Am. J. Eng. Res., pp. 223-226, 2016. [AJER]

[27] P.H. Sankar, M. Reddy, and A. Kumar, "The effect of fiber length on tensile properties of polyester resin composites reinforced by the fibers of sansevieria trifasciata", Int. Letters Natu. Sci., vol. 8, pp. 7-13, 2014.

[http://dx.doi.org/10.18052/www.scipress.com/ILNS.8.7]

[28] P. Amuthakkannan, V. Manikandan, and W. Jappes, Material Physics and Mechanics, vol. 16, pp. 107-117, 2013.

[29] J. Dalvi, "Effect of fibre length and percentage of sisal on strength of concrete", Multidiscip. J. Res. Engi. Tech., vol. 3, no. 1, pp. 923-932, 2016 .

\section{(C) 2021 Tunje et al.}

This is an open access article distributed under the terms of the Creative Commons Attribution 4.0 International Public License (CC-BY 4.0), a copy of which is available at: https://creativecommons.org/licenses/by/4.0/legalcode. This license permits unrestricted use, distribution, and reproduction in any medium, provided the original author and source are credited. 